\title{
CULTURAL HERITAGE THROUGH TIME: A CASE STUDY AT HADRIAN'S WALL, UNITED KINGDOM
}

\author{
K. D. Fieber ${ }^{\text {a }}$, J. P. Mills ${ }^{\text {a }}$, M. V. Peppa ${ }^{\text {a }}$, I. Haynes ${ }^{\text {b }}$, S. Turner ${ }^{\text {b }}$, A. Turner ${ }^{\text {b }}$, M. Douglas ${ }^{\text {c }}$, P. G. Bryan ${ }^{\text {d }}$ \\ a School of Civil Engineering and Geosciences, Newcastle University, Newcastle upon Tyne, NE1 7RU, UK - \\ (karolina.fieber, jon.mills, m.v.peppa)@ncl.ac.uk \\ ${ }^{\mathrm{b}}$ School of History, Classics and Archaeology, Newcastle University, Newcastle upon Tyne, NE1 7RU, UK - \\ (ian.haynes, sam.turner, alex.turner)@ncl.ac.uk \\ ${ }^{c}$ English Heritage, York, UK - \\ mark.douglas@english-heritage.org.uk \\ ${ }^{\mathrm{d}}$ Historic England, York, UK - \\ paul.bryan@historicengland.org.uk
}

\section{Commission II}

KEY WORDS: 4D Modelling, Cultural Heritage, Data Collection, Data Fusion, Monitoring, Visualization.

\begin{abstract}
:
Diachronic studies are central to cultural heritage research for the investigation of change, from landscape to architectural scales. Temporal analyses and multi-temporal 3D reconstruction are fundamental for maintaining and safeguarding all forms of cultural heritage. Such studies form the basis for any kind of decision regarding intervention on cultural heritage, helping assess the risks and issues involved. This article introduces a European-wide project, entitled "Cultural Heritage Through Time", and the case study research carried out as a component of the project in the UK. The paper outlines the initial stages of the case study of landscape change at three locations on Hadrian's Wall, namely Beckfoot Roman Fort, Birdoswald Roman Fort and Corbridge Roman Station, all once part of the Roman Empire's north-west frontier. The main aim of the case study is to integrate heterogeneous information derived from a range of sources to help inform understanding of temporal aspects of landscape change. In particular, the study sites are at risk from natural hazards, notably erosion and flooding. The paper focuses on data collection and collation aspects, including an extensive archive search and field survey, as well as the methodology and preliminary data processing.
\end{abstract}

\section{INTRODUCTION}

Cultural heritage sites and monuments are often taken in isolation, without consideration of historical changes or the surrounding environment. Nevertheless, diachronic change and landscape factors are important, constituting integral aspects of any site, and as such should be considered inseparable when developing strategies to document, maintain and conserve cultural heritage. Modern surveying techniques allow precise measurements and subsequent 3D modelling of the current state of cultural heritage, while no longer existing (damaged or missing) elements can be reconstructed using archival data such as drawings, paintings, historic photographs and archaeological analysis with the aid of computer vision and visualisation techniques.

Previous studies have focused on change detection (Patias et al., 2011), land cover dynamic investigation (Ratcliffe and Henebry, 2004), urban infrastructure analysis (Vizzari, 2011) and visualization (El-Hakim et al., 2008). Few have integrated data from different sources (De Luca et al., 2010; El-Hakim et al., 2008; Micoli et al., 2013; Patias et al., 2011), allowing for interdisciplinary interactions and leading to better understanding and reconstruction, as well as improved accessibility and visibility of cultural resources.

"Cultural Heritage Through Time" $\left(\mathrm{CHT}^{2}, 2017\right)$ is a Europeanwide project in which the scope is to develop three-dimensional products which represent change over time, from landscape to architectural scale, to envisage and analyse lost scenarios or visualize changes due to human activities or interventions, as well as pollution, wars, earthquakes or other natural hazards. The main aim of the $\mathrm{CHT}^{2}$ project is to merge heterogeneous information and expertise to deliver enhanced four-dimensional (4D) digital products for heritage sites. $\mathrm{CHT}^{2}$ is focussing on the full integration of the temporal dimension, its management and visualization, for studying and analysing cultural heritage structures and landscapes through time. Made possible thanks to co-funding from the Italian, Polish, Spanish and UK research councils under the framework of the "Joint Programming Initiative on Cultural Heritage" (JPI-CH, 2017), the project includes case studies in each of the four participating countries: the city centre of Milan, Italy; the fortress city of Krakow, Poland; the medieval walls of Avila, Spain; Hadrian's Wall and its landscape, UK.

The main focus of the case study presented here is Hadrian's Wall, stretching from the west to the east coast of Northern England, once a frontier of the Roman Empire. Three particular locations along the wall were selected for analysis: Beckfoot (Bibra) Roman Fort, located furthest west on the Cumbrian coast; Birdoswald Roman Fort, sited more centrally; and Corbridge (Corstopitum) Roman Station, situated furthest east of the three (Figure 1). Emphasis was placed on the temporal aspect of landscape change caused by coastal, fluvial and soil erosion

\footnotetext{
* Corresponding author
} 
(depending on the site) and its impact on cultural heritage with implications for management of historic sites and the benefit of interpretation for stakeholders.

\section{HISTORICAL CONTEXT}

Around AD 122 the Roman Emperor Hadrian ordered a wall to be built, dividing Britain in half. Stretching over $117 \mathrm{~km}(80$ Roman miles) from Bowness on the River Solway on the northwest coast of England to Wallsend on the River Tyne in the northeast, it was to become one of the most heavily defended frontiers of the Roman Empire. It is believed to have taken three legions of infantrymen from the army of Britain around six years to complete. The Wall, complemented by a sophisticated system of outposts and coastal watch stations, offers a remarkable glimpse of ancient society. In addition to housing one of the largest concentrations of Roman soldiers anywhere in the Empire's provinces, Hadrian's frontier system was home to a cosmopolitan array of civilians.

The Wall is Britain's finest, most widely known and largest Roman monument. However, the Wall today (Hadrian's Wall, 2017), a designated UNESCO World Heritage Site since 1987, and its surrounding landscape is very different to that of Roman times. Although significant portions are still visible in coastal, rural and urban settings, the remaining fabric and landscape of the Wall are subject to various modern day stresses, for example tourism, urban development and natural hazards, making the Wall an ideal case study for the $\mathrm{CHT}^{2}$ project.

\section{STUDY AREA}

The $\mathrm{CHT}^{2} \mathrm{UK}$ case study focusses on three different sites located along Hadrian's Wall (Figure 1) that characterise natural hazard phenomena facing the Wall in the 21st Century.

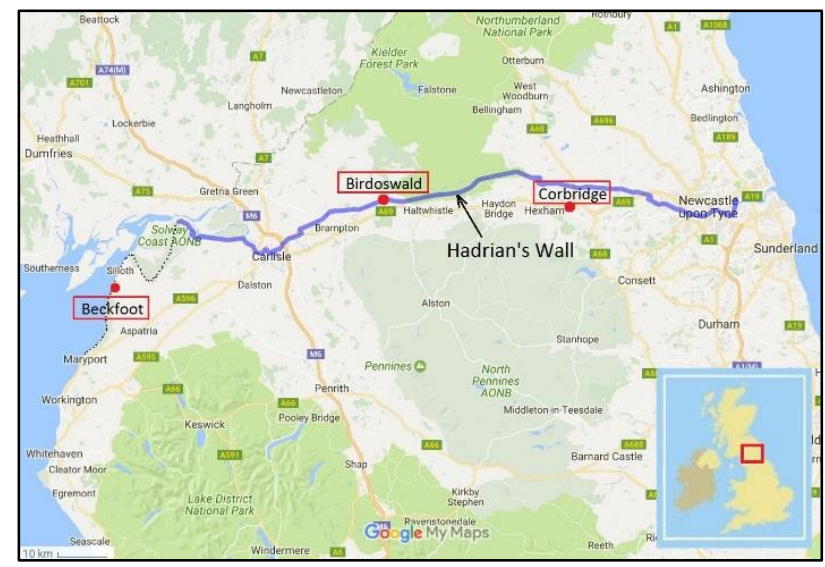

Figure 1: Location map of $\mathrm{CHT}^{2} \mathrm{UK}$ study sites overlaid on Google Maps.

\subsection{Beckfoot Roman Fort}

The fort (Bibra), civilian settlement and cemetery at Beckfoot (Historic England, 2017a), located to the south-west of the main Wall, is the least studied and documented site of the three chosen study areas. The fort is preserved as a cropmark, with analysis of aerial photographs revealing clear details of building outlines (Figure 2) and with partial excavation indicating extensive survival of building and defensive wall foundations. The
Beckfoot site has been subject to significant coastal erosion over recent centuries, with archaeology buried under sand dunes being frequently exposed by coastal processes.

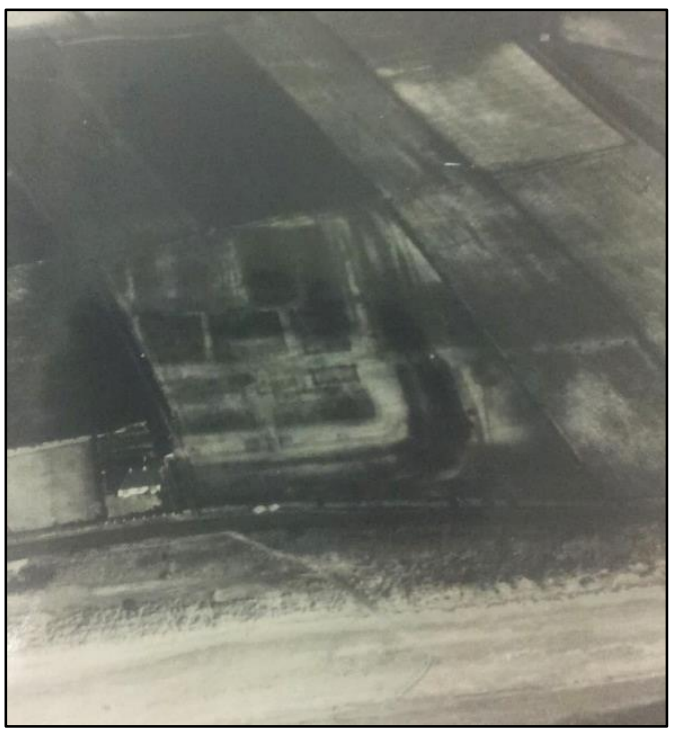

Figure 2: Beckfoot Fort outlines seen from the air, with beach and sand dune complex in the foreground, viewed from the west c.1949 (University of Newcastle upon Tyne Air Photograph Collection, NY/0848/A).

\subsection{Birdoswald Roman Fort}

Birdoswald (Historic England, 2017b) is one of the best preserved of the 16 forts built as part of the Hadrian's Wall frontier system. The monument includes the Roman Fort (Figure 3 ) and the section of Hadrian's Wall and vallum between the River Irthing to the east and the field boundaries east of Harrow Scar milecastle 50 to the west. The excavated area of the fort, managed by English Heritage, is open to visitors but is at critical risk to landslides instigated by fluvial erosion from the River Irthing running along the south of the site.

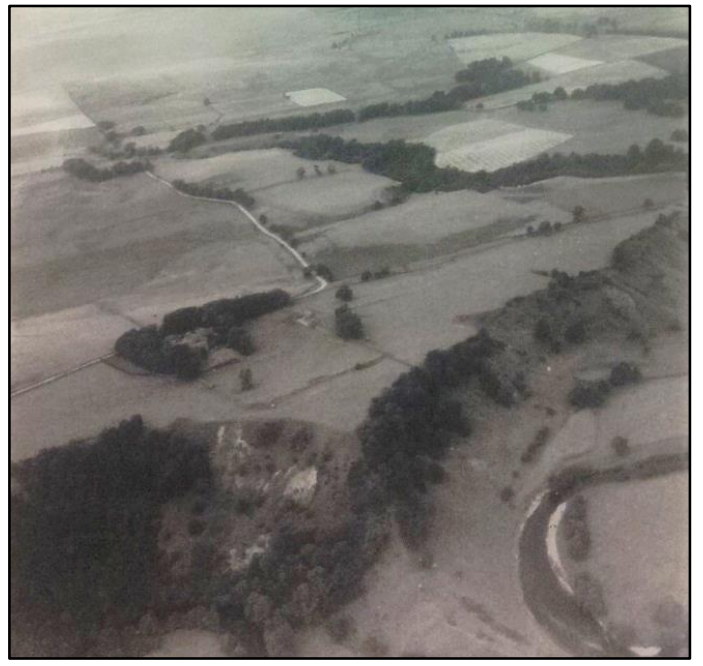

Figure 3: Birdoswald Fort seen from the air, viewed from the south-west c. 1947 (University of Newcastle upon Tyne Air Photograph Collection, NY/6166/A, copyright Cambridge University). 


\subsection{Corbridge Roman Station}

The Roman town of Corbridge (Historic England, 2017c) marks the site of the most northerly urban settlement in the Roman Empire. The streets of the town have been excavated and are open to the public under English Heritage management. The site is subject to fluvial flood hazard from the River Tyne to the south.

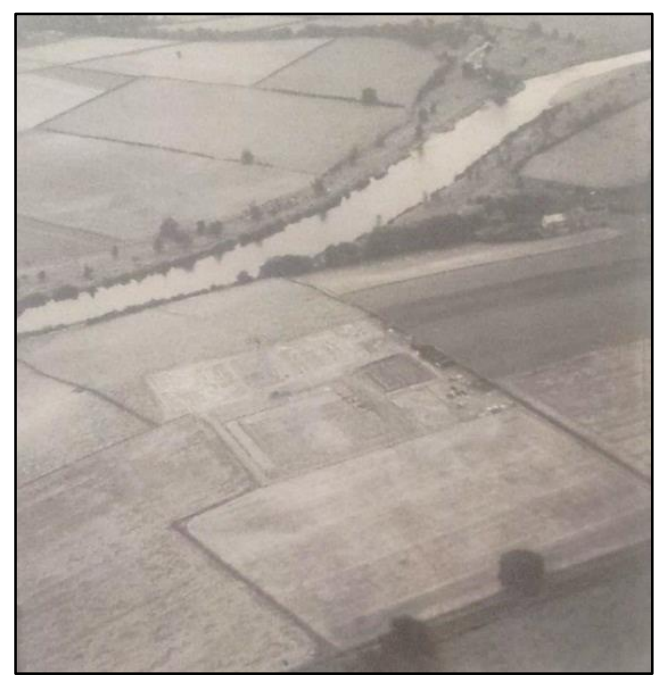

Figure 4: Corbridge Roman Town seen from the air, viewed from the northeast c. 1945 (University of Newcastle upon Tyne Air Photograph Collection, NY/9864/A, copyright Cambridge University).

\section{METHODS}

Data for all study sites were processed following the $\mathrm{CHT}^{2}$ designated workflow (Figure 5). The methodology pipeline is divided into four main phases: (i) data collection, (ii) processing, (iii) fusion and (iv) analysis of results $\left(\mathrm{CHT}^{2}\right.$ WP2, 2016; Rodríguez-Gonzálvez et al., 2017). This paper focuses primarily on the first phase of the methodology, the data collection stage. This step includes both historical and current data and is described in Figure 5, based on the main source of data from which it originates.

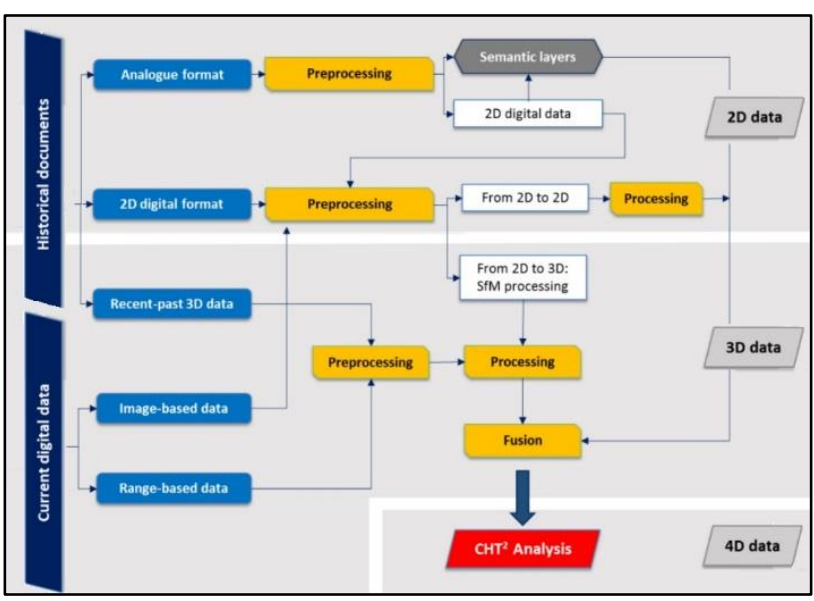

Figure 5: Simplified diagram of the methodology proposed for the integration of cultural heritage data in order to perform 4D analysis $\left(\mathrm{CHT}^{2}\right.$ WP2, 2016).
In the first instance, an extensive archive search was conducted in order to identify existing materials, with particular focus on historic aerial photographs, including the Historic England Archive and Newcastle University's archives. Although more data were available, three epochs of aerial photograph datasets were initially selected for each of the sites: one from the 1940's, one form the 1980's or 1990's and one modern dataset acquired in 2016.

The archival photography was subsequently digitised at high resolution (600 dpi for the earliest datasets, $2000 \mathrm{dpi}$ for 1980's/90's) by the Historic England Archive (note that digitisation was not performed using a photogrammetric scanner, and the resultant imagery is therefore likely subject to distortions - e.g. Thomas et al., 1995). The 2016 photography was provided by Historic England in digital format for Birdoswald and Corbridge sites. Due to the fact that such photography did not exist for Beckfoot at the time of the archive search, an Unmanned Aerial Vehicle (UAV) survey was performed in order to complete the time series for that site.

Aerial photography was complemented by other data stored at and provided by English Heritage. These included historic topographic maps, topographic and geophysical surveys and drawings. Furthermore, LiDAR point cloud data were obtained for all three sites from the Environment Agency's repositories (Environment Agency, 2017). Finally, LiDAR data of Birdoswald acquired in 2008, being in possession of Newcastle University (Miller et al., 2012), were added to the time series (e.g. Figure 6).

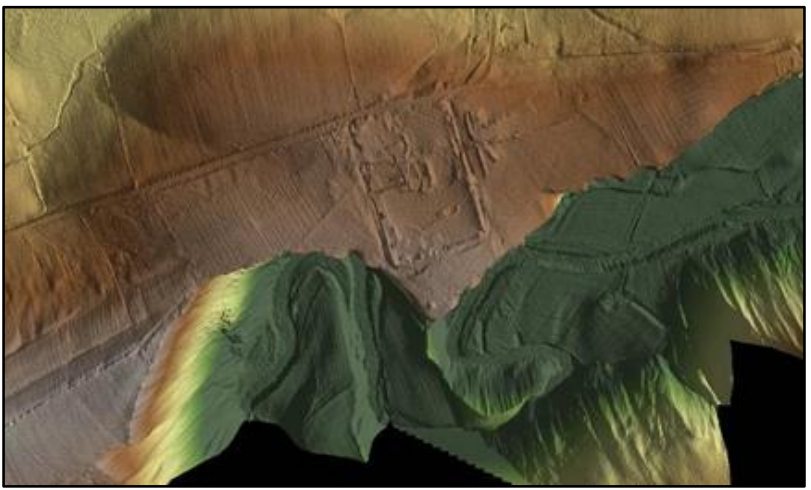

Figure 6: 2008 airborne laser scan of Birdoswald Roman Fort and surrounds.

\section{UAV SURVEY}

A UAV survey was carried out at Beckfoot on $15^{\text {th }}$ September 2016 by Geomatics researchers of Newcastle University. A Quest300 fixed-wing UAV (QuestUAV Ltd., Amble, UK), owned by Newcastle University was used for the survey. This UAV can carry a maximum $5 \mathrm{~kg}$ of payload with approximately 15-minute flight time. The system contains an on-board singlefrequency Global Navigation Satellite System (GNSS) receiver, a consumer-grade Micro-Electro Mechanical System - Inertial Measurement Unit (MEMS-IMU) and a micro-processor with autopilot software. The latter facilitates autonomous UAV flights using pre-programmed flight plan parameters. Peppa et al. (2016) provides further details and specifications of the UAV.

Two gimballed Panasonic DMC-LX5 digital cameras (Panasonic UK Ltd.) were mounted on-board the UAV at the time of survey. 
One Panasonic camera was a standard camera sensitive to visible light (RGB), whilst the second was modified to be sensitive to near infrared (NIR) wavelengths (three NIR bands). The cameras have an $8.07 \times 5.56 \mathrm{~mm}$ CCD sensor of $3648 \times 2736$ pixels, yielding a nominal pixel size of $2 \mu \mathrm{m}$. Setting the flying altitude to $91 \mathrm{~m}(300 \mathrm{ft})$ and with camera focal length of $5 \mathrm{~mm}$ enabled a $4 \mathrm{~cm}$ ground sampling distance for the acquired images. With a maximum of 15-minute flight time, the Beckfoot area was divided into two overlapping parts (north and south) and surveyed under two separate sorties (Figure 7).

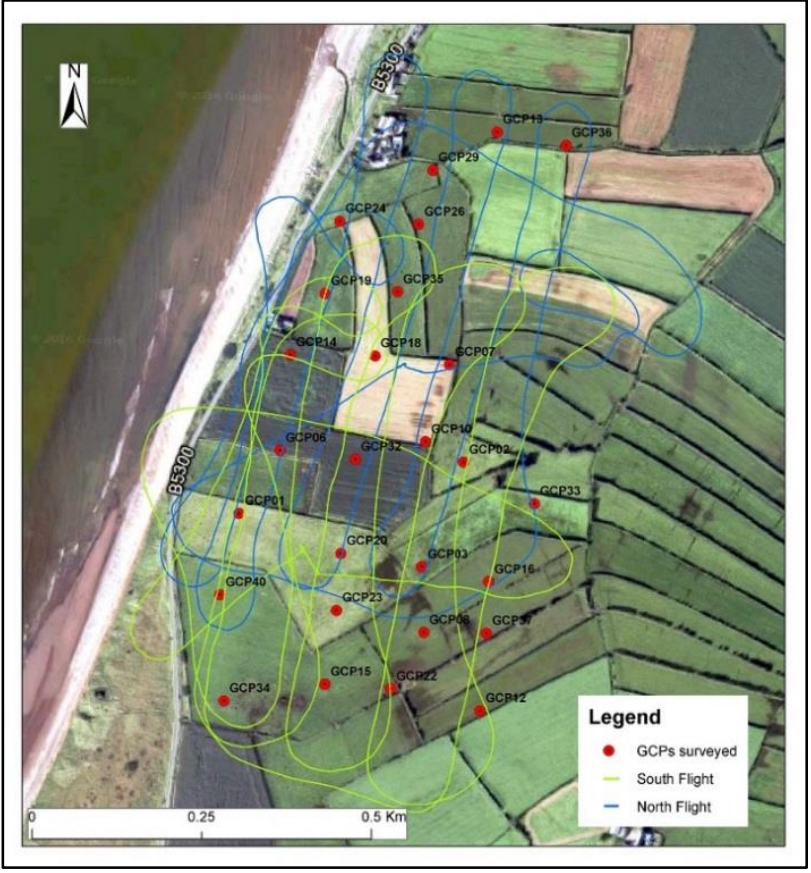

Figure 7: Beckfoot site with flight paths and GCPs location overlaid. Background image: Google Maps.

A GNSS base station was established on one of the fields and observed in GNSS static mode for approximately four hours, delivering $1 \mathrm{~cm}$ planimetric and $2 \mathrm{~cm}$ vertical absolute accuracy. 27 circular control point targets of $0.40 \mathrm{~m}$ diameter were evenly distributed over the site (except for north east corner where no access to the fields was granted) and were surveyed in GNSS rapid static mode (five-minute observations), which delivered 3D accuracy at mm-level relative to the GNSS base station. The camera was set up with a fixed shutter speed of $1 / 800 \mathrm{~s}$ to decrease image blurring, a fixed aperture of $\mathrm{f} / 2$ and ISO 100 . The exposure interval was set to 2 seconds and the side overlap to $80 \%$.

Ground Reflectance Calibration Targets were also placed on site (near GCP01) at the time of survey to enable calibration of RGB and NIR imagery. These targets comprised four lightweight wood boards each measuring $1.2 \times 1.2 \times 0.01 \mathrm{~m}$, which were painted black and three different grey tones with matt paint (Berra et al., 2017). Spectral measurements of the targets were acquired with an ASD field spectrometer (FieldSpec Pro, ASD Inc., CO, U.S.), using an 8 degree fore optic accessory positioned at nadir, $1.5 \mathrm{~m}$ above the target's surface. A 24 " white barium sulphate-based panel (LabSphere, Inc. NH, U.S.) was used as a white reference (Berra et al., 2017).

The UAV survey at Beckfoot was augmented by archaeological excavations and geophysical survey, including gradiometry and resistivity, carried out by a team of archaeologists from Newcastle University in June and September 2016.

\section{DATA PROCESSING}

Both archival and modern photography were processed to generate three-dimensional data. Since archival imagery was not scanned on a photogrammetric scanner and the camera calibration information was unavailable, the structure-frommotion ( $\mathrm{SfM}$ ) pipeline was adopted in order to obtain digital surface and terrain models for each site and to facilitate multitemporal landscape comparisons. Agisoft Photoscan (Version 1.2.4.) software was used for this task.

SfM is the process of simultaneously estimating three dimensional geometry (structure) and camera pose (motion) from a series of overlapping offset images based on matching common features (Ullman, 1979). The SfM workflow can be divided into several stages, where the first step is to find key feature points and match them between image pairs. The matches are then organised into connected sets of matching key points across multiple images. Finally, the scene is reconstructed incrementally, a few images at a time, using a bundle adjustment procedure. The result of processing is a photogrammetric "point cloud" representative of the scene.

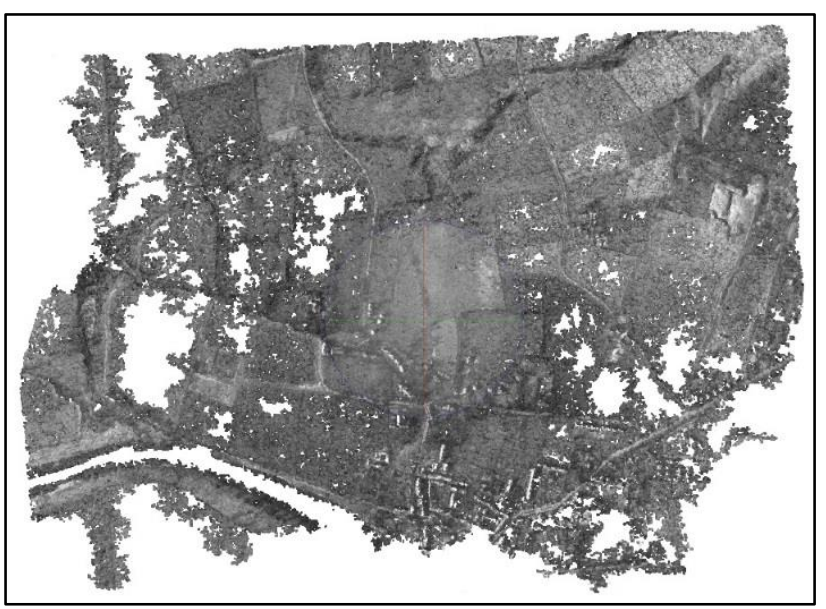

Figure 8: 1946 dense point cloud of Corbridge landscape generated from archive photographs supplied by Historic England / English Heritage.

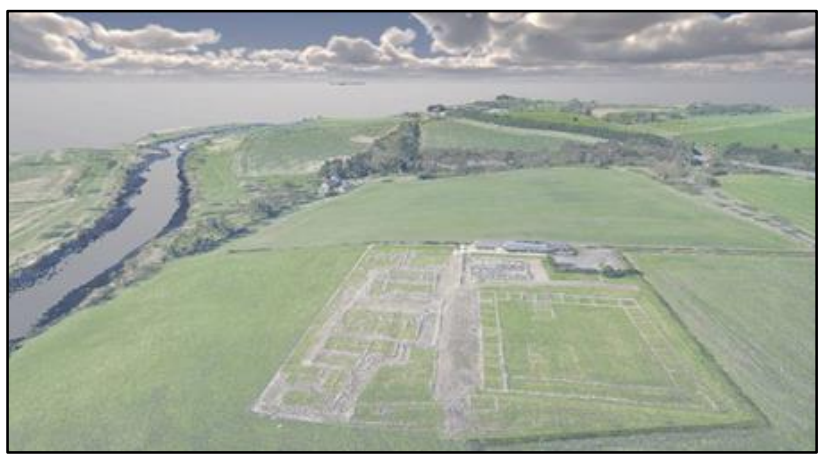

Figure 9: Visualisation of 2016 Corbridge landscape generated in Geovisionary from archive photographs supplied by Historic England / English Heritage. 
3D SfM point clouds (e.g. Figure 8) for each individual epoch were geocoded using selected terrain features, considered to have remained stable over the years, or measured GCPs in the case of the Beckfoot 2016 survey data. This allowed for approximate alignment of the datasets in the OSGB36 coordinate system. Alignments were further refined using various approaches, including both in-house surface matching algorithms (Miller et al., 2008) and ICP (Besl and McKay, 1992) routines in the OPALS software (Pfeifer et al., 2014), to ensure rigorous registration from epoch to epoch, thereby generating spatially consistent 3D time series for subsequent cultural heritage analysis. Finally, data were gathered in ArcGIS 10.3.1 (ESRI Inc.) and Geovisionary 3 (Virtalis) software to enable visualisations (e.g. Figure 9) and spatio-temporal analysis.

\section{CONCLUSIONS AND FUTURE WORK}

This paper has outlined the research undertaken as part of the "Cultural Heritage Through Time" European project, focussing on documentation, modelling and analysis of three Roman fortification sites on Hadrian's Wall, UK. The article has described the initial stages of the case study, including data collection and processing. The study aims at analysing landscape change due to natural hazards such as fluvial and coastal erosion. The results of data analysis will be presented in a future paper.

The ambition is for future research to extend the temporal range of the time series for each of the study site landscapes. This will be attempted both historically, by exploiting newly captured ground penetrating radar data at each site, and prospectively into the future, by exploiting the compiled datasets to inform appropriate numerical models to predict coastal and fluvial evolution of the landscapes. In order to maximise the value of research outcomes by promoting their transfer to individuals and organisations, $\mathrm{CHT}^{2}$ is also considering ways to best visualise and disseminate results. An example of such a visualisation from the Corbridge dataset is given in Figure 9. Material from the project is also feeding into a Newcastle University Massive Online Open Course (MOOC), entitled Hadrian's Wall: Life on the Roman Frontier. This free to participate MOOC is available at FutureLearn (2017).

\section{ACKNOWLEDGEMENTS}

The authors wish to acknowledge the support of the European Union Joint Programming Initiative on Cultural Heritage (JPI$\mathrm{CH})$, through national research authorities: UK Arts and Humanities Research Council (AHRC, award number AH/N504440/1), Spanish Ministry of Economy and Competitiveness, and Polish Ministry of Culture and National Heritage. The authors wish to acknowledge the support of English Heritage and Historic England in the provision of aerial photography and other archival materials. The authors would also like to thank the team who assisted with the UAV survey at Beckfoot: E. Berra, P. Chidburee and W. M. Robertson, as well as J. Murray who made the survey possible by arranging access to the site.

\section{REFERENCES}

Berra, E., Gaulton, R., Barr, S., 2017. Commercial Off-the-shelf Digital Cameras on Unmanned Aerial Vehicles for Multi Temporal Monitoring of Vegetation Reflectance and NDVI.
IEEE Transactions on Geoscience and Remote Sensing. (in press).

Besl, P., McKay, N., 1992. A method for registration of 3-D shapes. IEEE Trans. Pattern Anal. Mach. Intell. 14 (2), 239-256.

$\mathrm{CHT}^{2}$, 2017. Cultural Heritage Through Time. http://cht2project.eu, (Accessed January 2017).

CHT $^{2}$ WP2, U., 2016. WP2: Methodology Definition/4D Visualization, in: Gonzalez-Aguilera, D. (Ed.), Cultural Heritage Through Time. Salamanca University (USAL), Spain, p. 25.

De Luca, L., Stefani, C., Renaudin, N., Busarayat, C., Véron, P., Florenzano, M., 2010. An Iconography-Based Modeling Approach for the Spatio-Temporal Analysis of Architectural Heritage, International Conference on Shape Modeling and Applications, pp. 78-89.

El-Hakim, S.F., Lapointe, J.-F., Whiting, E., 2008. Digital reconstruction and 4D presentation through time, Association for Computing Machinery SIGGRAPH 2008 talks (ACM SIGGRAPH '08), New York, NY, USA.

Environment Agency, 2017. Lidar Data.

https://data.gov.uk/publisher/environment-agency, (Accessed January 2017)

FutureLearn, 2017. Hadrian's Wall: Life on the Roman Frontier. https://www.futurelearn.com/courses/hadrians-wall, (Accessed January 2017).

Hadrian's Wall, 2017. Hadrian's Wall Country. http://hadrianswallcountry.co.uk, (Accessed January 2017).

Historic England, 2017a. Beckfoot Roman Fort. https://historicengland.org.uk/listing/the-list/list-entry/1007170, (Accessed January 2017).

Historic England, 2017b. Birdoswald Roman Fort. https://historicengland.org.uk/listing/the-list/list-entry/1010994, (Accessed January 2017).

Historic England, 2017c. Corbridge (Corstopitum) Roman Station. https://historicengland.org.uk/listing/the-list/listentry/1006611, (Accessed January 2017).

JPI-CH, 2017. Joint Programming Initiative on Cultural Heritage. http://www.jpi-culturalheritage.eu/, (Accessed January 2017)

Micoli, L., Guidi, G., Angheleddu, D., Russo, M., 2013. A multidisciplinary approach to 3D survey and reconstruction of historical buildings, 2013 Digital Heritage International Congress (DigitalHeritage), pp. 241-248.

Miller, P., Mills, J., Edwards, S., Bryan, P., Marsh, S., Mitchell, H., Hobbs, P., 2008. A robust surface matching technique for coastal geohazard assessment and management. ISPRS Journal of Photogrammetry and Remote Sensing, 63(5): 529-542.

Miller, P. E., Mills, J. P., Barr, S. L., Birkinshaw, S. J., Hardy, A. J., Parkin, G., Hall, S. J., 2012. A remote sensing approach for landslide hazard assessment on engineered slopes. IEEE Transactions on Geoscience and Remote Sensing, 50(4), pp. 1048-1056. 
Patias, P., Kaimaris, D., Stylianidis, E., 2011. Change detection in historical city centers using multi-source data: the case of historical center of Nicosia - Cyprus, 23rd International CIPA Conference, Prague, Czech Republic.

Peppa, M. V., Mills, J. P., Moore, P., Miller, P. E., Chambers, J. E., 2016. Accuracy assessment of a UAV-based landslide monitoring system. International Archives of Photogrammetry, Remote Sensing and Spatial Information Sciences, 42(5), pp. 895-902.

Pfeifer, N., Mandlburger, G., Otepka, J., Karel, W., 2014. OPALS - A framework for Airborne Laser Scanning data analysis. Computers, Environment and Urban Systems, 45, pp. 125-136.

Ratcliffe, I.C., Henebry, G.M., 2004. Using declassified intelligence satellite photographs with Quickbird imagery to study urban land cover dynamics: a case study from Kazakhstan, Annual ASPRS Conference, Denver, Colorado, pp. 1-10.

Rodríguez-Gonzálvez, P., Muñoz-Nieto, A.L., del Pozo, S., Sanchez-Aparicio, L.J., Gonzalez-Aguilera, D., Micoli, L., Gonizzi Barsanti, S., Guidi, G., Mills, J., Fieber, K., Haynes, I., Hejmanowska, B., 2017. 4D Recontruction and Visualization of Cultural Heritage: Analyzing Our Legacy Through Time, 3D Arch Workshop, Nafplio, Greece.

Thomas, P. R., Mills, J. P., Newton, I., 1995. An investigation into the use of Kodak Photo CD for digital photogrammetry. Photogrammetric Record, 15(86), pp. 301-314.

Ullman, S., 1979. The interpretation of structure from motion. Proceeding of Royal Society of London B-203, 405-442.

Vizzari, M., 2011. Spatio-Temporal Analysis Using Urban-Rural Gradient Modelling and Landscape Metrics, in: Murgante, B., Gervasi, O., Iglesias, A., Taniar, D., Apduhan, B.O. (Eds.), Computational Science and Its Applications - ICCSA 2011: International Conference, Santander, Spain, June 20-23, 2011. Proceedings, Part I. Springer Berlin Heidelberg, Berlin, Heidelberg, pp. 103-118. 